\title{
O DISCURSO DA MÍDIA: A INTERAÇÃO NAS ENTREVISTAS DE TV
}

\author{
Maria Lúcia da Cunha V. de Oliveira Andrade*
}

Em suas várias aplicações, a entrevista é uma técnica de interação social. Por meio dela, busca-se uma interpenetração informativa que visa a quebrar isolamentos sociais pode ainda servir à pluralização de vozes e à distribuição democrática da informação, constituindo sempre um meio cujo objetivo fundamental é o inter-relacionamento humano.

Em toda a entrevista, além de se pretender uma troca de informações, de experiências, de juízos de valor, há uma ambição mais ousada que Buber (1982) já dimensionou: o diálogo em que a relação eu-tu é plena, isto é, entrevistador e entrevistado saem "modificados" do encontro, porque houve interação, ambos se revelaram, cresceram no conhecimento do mundo e deles próprios.

Este trabalho se volta para o estudo das digressões em entrevistas de televisão, tendo como corpus dois programas distintos: Entrevista Coletiva, transmitido pela rede Bandeirantes e Jô Onze e Meia, veiculado pelo SBT. Devido a essa seleção, o centro de interesse estará voltado, por um lado, para entrevistas em que ocorre certa polemização, já que se instaura o debate de idéias, o confronto de opiniões; por outro, para aquelas onde se traça um perfil humano.

Em síntese, esta pesquisa busca tratar a digressão, verificando em que medida, ao empregar essa estratégia, a interação recebe uma espécie de reorientação de seu sentido, revelando algo que está no horizonte do campo de percepção do locutor. 
ANDRADE, Maria Lúcia da Cunha V. de Oliveira. O discurso da mídia: a interação nas entrevistas de TV.

Pretende-se verificar também como a digressão apresenta papéis definidos na construção textual.

Nas entrevistas os interlocutores representam seu papel discursivo e de identidade (entrevistador/entrevistado) que pode ser definido como o conjunto de direitos e deveres comunicativos, associados aos papéis dos interagentes e ao desempenho de uma identidade social.

Importa salientar a configuração espacial dos programas que servem como corpus para este trabalho. No que se refere ao Programa Jô Onze e Meia, tem-se uma proximidade física entre entrevistador e entrevistado e há um caráter de intimidade entre os participantes. Este programa insere-se no gênero talk show, termo que indica toda forma de palavra dialogada veiculada pela televisão. Segundo Machado (1996: 101), este tipo de programa não visa ao sensacionalismo ou à polêmica: "o talk show prima por seu aspecto consensual e intimista e por tentar estabelecer uma relação de confiança entre o entrevistador e convidados, diante de um dado público".

O apresentador Jô Soares acumula várias funções e pode ser designado apresentador-vedete, já que o culto à personalidade do animador é uma característica fundamental do programa. $\mathrm{O}$ entrevistador prima por parecer simpático, tenta criar um ambiente agradável para que a situação comunicativa se instaure.

$\mathrm{Na}$ abertura do programa, o animador apresenta-se sentado de frente para a platéia e para o telespectador; entretanto, no momento da entrevista assume a postura semifrontal, colocando-se de lado, em relação ao público. "Quando quer fazer alguma pergunta, o animador inclina-se para seu convidado: sua aproximação e seu afastamento vão indicar, respectivamente, o início e o término das unidades discursivas de comunicação" (Machado, 1996: 103-104). Cabe apontar que o animador mantém uma distância interpessoal que favorece o toque (criador de um certo efeito de intimidade), feito sempre ao término da entrevista.

O Programa Jô Onze e Meia tem uma espécie de compromisso com o "fazer espetáculo", o que prioriza o divertir em detrimento do informar. Diferentemente, os programas Entrevista Coletiva ou Juca Kfouri primam pela informação e enquadramse na entrevista jornalística. Esses dois programas não possuem platéia, porém o telespectador pode participar de modo mais efetivo através de fax ou via Internet. Em muitas entrevistas, principalmente aquelas feitas com políticos, instaura-se um discurso polêmico gerador de situações onde emerge o conflito.

Os programas de entrevista foram se modificando ao longo do tempo e não têm mais como ponto de referência perguntas e respostas que visam a preencher um 
espaço de tempo pouco significativo. Segundo Aquino (1997: 98), a entrevista desenvolve-se com base em perguntas, mas a partir da direção que se dê a elas, o entrevistador perspicaz - num estilo próprio - utiliza-se de estratégias variadas para a obtenção de boas respostas. Um entrevistador eficaz consegue, muitas vezes, a revelação de material secreto e chega até a conseguir revelações íntimas de forma sutil.

Para poder processar o seu texto, o interlocutor ativa sua percepção em relação à situação comunicativa. Esta, por sua vez, é acionada a partir de um conjunto pertinente de instruções para a conduta verbal na referida situação. Verifica-se, assim, que o contexto situacional determina as condições pragmáticas vigentes durante a interação verbal. Em outras palavras, o contexto situacional é a construção cognitiva (ou quadro) que o falante faz da situação comunicativa.

A percepção da situação ocupa um lugar especial nesse contexto. O falante percebe somente aqueles elementos da realidade circundante que considera relevantes para o desenvolvimento da interação. Assim, pode-se asseverar que o contexto situacional é uma criação individual. Mas para que esta criação se efetive os demais contextos (cultural, biográfico individual e conhecimento de mundo) são acionados.

$\mathrm{Na}$ construção de um texto em que se instaura uma digressão (tipo de movimento tópico que suspende momentaneamente o tópico discursivo prévio, instaurando um outro domínio de relevância), verifica-se que o falante traz para o contexto situacional algo que é próprio do contexto biográfico e/ou do contexto de conhecimento de mundo, ou seja, trata de influenciar a constituição do contexto situacional no outro interactante, em função de sua metas comunicativas, criando uma digressão lógico-experiencial, visto que o foco da cena discursiva é direcionado para um propósito de natureza pessoal. Neste caso, há negociação individual ou negociação de contexto em função do quadro de relevâncias que se estabelece na interação. Por sua vez, o falante pode evidenciar no contexto situacional elementos do contexto cultural, já que se tornam relevantes, motivacionalmente, elementos externos ou regras de conduta da atividade social, estabelecendo uma digressão interpessoal incidental. $\mathrm{O}$ falante pode ainda introduzir uma digressão interpessoal imediata ao fazer uso da relação existente entre ele próprio e a pertinência de algum elemento ou objeto presente no entorno. Por fim, o falante pode estabelecer um vínculo de pertinência textual, ou seja, contribuir para a textura da produção lingüística, instaurando no contexto situacional elementos relevantes ao contexto cultural, biográfico individual ou de conhecimento de mundo. Neste caso, tem-se uma digressão retórica. 
Entretanto, um dos locutores pode fazer uma pergunta não para solicitar qualquer esclarecimento, mas para manipular seu interlocutor, orientando seus argumentos de alguma maneira. Um exemplo característico desse tipo de digressão se instaura quando o locutor cria uma paráfrase da pergunta com a finalidade de direcioná-la para certo objetivo, estabelecendo uma digressão retórica persuasiva.

As digressões podem ser definidas como uma estratégia por meio da qual os interlocutores conduzem o texto falado, manifestando na materialidade lingüística o quadro de relevância acionado na situação enunciativa. O deslocamento e conseqüente focalização de um novo ponto no domínio de relevância se instaura a partir da percepção de um dos participantes e se efetiva por meio de marcas formais que apontam para algo que estava no entorno e que agora foi inserido no contexto situacional.

Ao se afirmar que, por meio da digressão, a interação verbal recebe uma espécie de reorientação de seu sentido, pretendeu-se dizer que a digressão opera uma mudança de foco em relação ao tópico discursivo em andamento, revelando algo que está no horizonte do campo de percepção do falante. Desejou-se também colocar que a digressão tem papéis definidos na construção textual, de base informacional ou interacional na organização tópica. Isso se deve ao fato de que toda a digressão circunscreve a significação tópica no âmbito de significações mais amplas geradas pelo espaço discursivo, emergentes graças ao olhar que pelo menos um dos interlocutores lança em relação ao quadro discursivo no qual a interação se efetiva. Em outras palavras, a digressão revela o "lugar" de onde emerge a relevância de seu conteúdo agora contextualizado.

Por meio da explicitação verbal desse lugar de processamento discursivo, realiza-se a integração textual da digressão: focalizando e instaurando novas relevâncias, a digressão torna-se um tópico efetivo do texto, articulado aos demais, na medida em que espelha a geração de tais relevâncias, criando um movimento próprio.

De acordo com os objetivos, os interlocutores organizam suas ações de modo a alcançar os fins a que se propuseram no início da interação e que as digressões se instauram como estratégias discursivas na organização das entrevistas. Em outras palavras, toda a digressão instaura na significação tópica elementos que pertencem ao espaço discursivo em que se tornam emergentes devido à percepção de um dos interlocutores, evidenciando que o quadro discursivo se compõe de elementos centrais e marginais passíveis de se tornarem focais devido a uma escolha realizada durante a atividade interacional.

Para a construção do significado comunicativo da digressão torna-se fundamental a observação do contexto situacional e de que elementos dos demais contextos 
(cultural, biográfico-individual, conhecimento de mundo) afloram, determinando a configuração contextual e as condições pragmáticas vigentes durante a interação verbal. Assim, o contexto manifesta-se através de uma forma de relevância (central, marginal, motivacional ou metalingüística) que envolve a atividade conversacional quer como presença, quer como saber dos interlocutores.

\section{Bibliografia}

ANDRADE, M. L. C. V. O. (1995) Digressão: uma estratégia de condução do jogo textualinterativo. (Tese de Doutoramento) São Paulo: Universidade de São Paulo.

AQUINO, Z. G. O. de. (1997) Conversação e conflito: um estudo das estratégias discursivas em interações polêmicas. (Tese de Doutoramento) São Paulo: Universidade de São Paulo.

BUBER, M. (1982) Do diálogo e do dialógico. São Paulo: Perspectiva.

DASCAL, M. e KATRIEL, T. (1979) Digression a study in conversational coherence. In: PETOFI, J. S. (ed.). Text vs. Sentence. Hamburg: Buske, v. 29, p. 76-95.

GARRETT, A. (1981) A entrevista, seus principios e métodos. Rio de Janeiro: Agir.

HALPERÍN, J. (1995) La entrevista periodística: intimidades de la conversación pública. Buenos Aires: Paidós.

IBAÑEZ, R. El contexto del evento verbal. Trabalho apresentado no IX Congresso Internacional da ALFAL, Campinas (Brasil), de 6 a 10 ago. 1990, p. 21 (no prelo).

MACHADO, I. L. (1996) Análise discursiva de um gênero televisual: a entrevista no talk show Jô Soares Onze e Meia. In: CARNEIRO, A. D. (org.). O discurso da mídia. Rio de Janeiro: Oficina do Autor.

MEDINA, C. de A. (1986) Entrevista: o diálogo possível. São Paulo: Ática.

MORIN, E. (1973) A entrevista nas Ciências Sociais, na rádio e na televisão. In: MOLES, A. A. et alii. Linguagem da cultura de massa. Petrópolis: Vozes.

VIOLLET, C. (1986) Interaction verbale et pratiques d'interruption. DRLAV. 34-35: 183-193. 